\title{
Application of daily rainfall principal component analysis to the assessment of the rainy season characteristics in Senegal
}

\author{
Pierre Camberlin $^{1, *}$, Mbaye Diop ${ }^{2}$ \\ ${ }^{1}$ UMR 5080 CNRS, Centre de Recherches de Climatologie, Université de Bourgogne, 6 Bd Gabriel, 21000 Dijon, France \\ ${ }^{2}$ Laboratoire d'Enseignement et de Recherche en Géomatique (LERG), Campus universitaire de l'ESP, \\ BP 25275 Dakar-Fann, Sénégal
}

\begin{abstract}
The interannual variability of the onset and cessation dates of the rainy season (RS) in Senegal is analyzed over the 43 yr period 1950-1992, using daily rainfall data for 34 stations. The use of principal component analysis, based on rainfall only, is explored to identify aggregate, regional indexes for the onset and cessation of the rains. The minimum and maximum values of the cumulative scores of principal component 1, for each year, are used to locate the onset and cessation dates, respectively. Very distinct spatial rainfall patterns are found before and after the onset/cessation dates. Mean dates compare favorably with those based on other definitions, though our method is not meant to provide dates with a local, rigorous agronomic significance. Over 1950-1992, the timeseries for the cessation shows a significant trend towards earlier dates, with an abrupt shift occurring around 1970. There is also a small trend for a delayed onset of the rains. However, the interannual variability of onset is greater than that of cessation dates. Correlation between onset, cessation, duration and total rainfall amounts is generally significant, but not as high as expected. 1988 and 1989 are good illustrations, with nearly identical rainfall amounts but an onset delayed by 1.5 mo in 1988 as compared to 1989. Graphs obtained using this method provide other interesting information about the RS, such as the general performance of the RS in terms of total rainfall amount. Pronounced dry spells are easily located: 29 cases were found between 1950 and 1992, concentrated in the early part of the RS (June-July). 'False starts' of the rains can also be monitored; they were reported in 16 out of the 43 years. Frequencies of dry spells and false starts do not exhibit any particular long-term trends.
\end{abstract}

KEY WORDS: Interannual rainfall variability $\cdot$ Onset and cessation of the rains $\cdot$ Senegal $\cdot$ Spatial patterns $\cdot$ Dry spells

Resale or republication not permitted without written consent of the publisher

\section{INTRODUCTION}

The assessment and prediction of the onset and cessation dates of the rainy season (RS) is a key issue in those tropical countries which rely on rain-fed agriculture. In Senegal, agricultural activities mobilize almost $70 \%$ of the active population and have a strong contribution $(20 \%)$ to the GDP. On the whole, the growing season corresponds to the RS, whose length differs from one year to the next and one region to the other.
The strong dependence of crops on climate makes final production output highly variable, as both rainfall amounts and the onset and cessation of the rains are subject to marked space-time variability.

The methods for identifying onset and cessation dates can be divided into 2 main categories: those based on rainfall distribution (or more broadly the water balance), and those taking into account atmospheric dynamics. In the first category, there exists a huge number of methods, mostly applied on a station-by- 
station basis, and often for agroclimatological purposes. In northern Australia, Nicholls (1984) defined onset as the date on which $15 \%$ of the mean annual rainfall, at a given station, has occurred. In most agroclimatological definitions, and as shown in Stern et al. (1981), the requirement of a certain amount of rainfall (RR) over a number $(\mathrm{Nw})$ of days is complemented by that of a maximum number $(\mathrm{Nd})$ of dry days within a period of time (P) following the potential start. In Tanzania, Mhita \& Nassib (1987) defined the onset as the first week receiving at least $15 \mathrm{~mm}$, after a given date determined by local climatology and agricultural practices, provided that no $2 \mathrm{wk}$ dry spells occur in the next $4 \mathrm{wk}$. For West Africa, Dodd \& Jolliffe (2001) considered the onset to be the first period of 5 consecutive days in which at least $25 \mathrm{~mm}$ of rain falls, on condition that no dry period ( $7 \mathrm{~d}$ or more) occurs in the following $30 \mathrm{~d}$. For the same region, Omotosho et al. (2000) proposed that the onset is the beginning of the first 2 rains totaling $20 \mathrm{~mm}$ or more within $7 \mathrm{~d}$, followed by $2-3 \mathrm{wk}$, each with at least $50 \%$ of the local crop water requirement. At the AGRHYMET Centre in Niamey, the first occurrence of a $10 \mathrm{~mm}$ moisture content in the first $15 \mathrm{~cm}$ of the soil is considered as the start of the cropping season, provided that the crop water requirements are satisfied at $50 \%$ or more $20 \mathrm{~d}$ after (Samba 1998).

For agroclimatological applications, the onset should be determined on a station-by-station basis. However, if the ultimate goal is the prediction of the onset (not just its monitoring), it has to be defined on regional, and not purely local, grounds. In fact, local (especially daily) rainfall is affected by random convective events, which might locally give huge precipitation amounts, enough to shift the onset date by a few days or even weeks; but those events are intrinsically unpredictable. There is thus a need to identify events (if any) which are of a sufficiently large scale (and enduring), and which can thus be associated with similarly largescale atmospheric changes, possibly detected some days/weeks in advance. For instance, Marengo et al. (2001), whose aim was to relate variations of the onset of the rains to atmospheric dynamics, defined regionalscale onset dates for different parts of the Amazon Basin. The dates were computed by averaging daily rainfall data from many stations and constructing $5 \mathrm{~d}$ averages. Onset was the pentad in which rainfall exceeded a given threshold, provided that the average rainfall was well below the threshold for several pentads preceding onset and well above for several pentads after onset. A similar approach was followed for the determination of the end of the RS. However, the authors found that onset dates were sensitive to changes in the threshold.

An alternative, which constitutes the second category of methods, relies on atmospheric dynamics. The
Indian Meteorological Department considers both a sustained increase in the rainfall over southern India (Kerala) and changes in the lower tropospheric winds and humidity as essential features of the Indian summer monsoon onset (Joseph et al. 1994). However, the determination is subjective. For the Australian monsoon, Holland (1986), using filtered $850 \mathrm{hPa}$ wind over Darwin, fixed the onset as the first occurrence of westerlies. Hendon \& Liebmann (1990) combined wind and rainfall data to determine the monsoon onset over the same region and found it superior to definitions based on a single index. In West Africa, Omotosho (1992) and Omotosho et al. (2000) demonstrated that changes in both upper-air wind direction and surface equivalent potential temperature (representative of variations of moisture in the monsoon flow) herald rainfall onset.

The use of upper air data to monitor the onset of the rains is a plus, but such data are seldom available in the tropics, and one often has to resort to rainfall data only. Nicholls et al. (1982) provided evidence that in the Darwin region of northern Australia, a quantitative index for the wet season onset can be defined in terms of rainfall at a single station. However, it remains doubtful whether this applies to such a diverse country as Senegal, where mean annual rainfall ranges from 200 to $1500 \mathrm{~mm}$. Furthermore, the question is also whether a 'regional' onset date has some sense. There is evidence from the rest of West Africa that the answer to this question is 'yes'. Sultan \& Janicot (2000) demonstrated the existence of an abrupt latitudinal shift of the Inter-Tropical Convergence Zone (ITCZ) over West Africa. It occurs on average (1968-1990) in late June, resulting in the onset/strengthening of the rains in the Sudano-Sahelian belt. However, this applies to the central part of the subregion $\left(10^{\circ} \mathrm{W}-10^{\circ} \mathrm{E}\right)$; further west in Senegal it is known that the rains start and peak later than in central and eastern Sahel.

From the above results and requirements, 3 different objectives emerge for this study:

- propose a method which could be used to define regional, instead of local, onset and cessation dates for the wet season in Senegal, or at least part of it, based on rainfall information only (best available);

- check how representative the regional dates of rainfall variability are of onset and cessation in the various parts of the country;

- analyze the interannual variations of onset and cessation dates since the 1950s, and their relationship with the total duration of season as well as the rainfall amount.

We propose to use cumulative anomalies, applied to principal component analysis (PCA) of daily rainfall time-series, to portray the onset, cessation dates and intra-seasonal characteristics of the RS on a regional 
basis. After a presentation of the data and general methodology (Section 2), the definition of onset and cessation dates is discussed in Section 3. The results are next compared with those obtained from other methods (Section 4). We then analyze the interannual variability of the onset and cessation dates, as well as other intra-seasonal features, in Senegal (Section 5).

\section{DATA AND METHODOLOGY}

Daily rainfall data for 34 stations is used from the 43 yr period 1950-1992. Data originate from the 'Direction de la Météorologie Nationale', Dakar, Senegal. The stations have been selected based on the availability of long, uninterrupted time-series. For that reason, there is a concentration of the stations in the western part of the country, while the northeastern corner is less adequately covered.

The methodology is based on the use of cumulative rainfall anomalies to depict the development of the RS. Since the aim is to obtain onset and cessation dates relevant to a large area, the daily rainfall data in all the 34 stations are first subjected to a PCA, using the correlation matrix (which initially gives the same weight to all the stations in the input matrix). Compared to simple spatial averaging, PCA is superior in that it extracts rainfall co-variability for stations which exhibit similar temporal variations, rather than simply smoothing the daily rainfall fields. There is no a priori existence of regionally consistent rainfall variations in the area under study, nor is there a priori delimitation of regional boundaries. Each principal component will then summarize daily rainfall fluctuations for a group of stations, giving to each station a weight which depends upon the variability it shares with the other stations of the group. PCA is applied in the 'S-mode' (spatial) sense, i.e., taking the stations as variables and the days as observations.

Prior to the analysis, and in order to reduce the skewness of the data, each time-series is square-root transformed, as suggested in Bärring (1988). This additionally gives less weight to an isolated heavy shower than to comparatively lighter, but potentially more widespread rainfall. Only the 7 mo from May to November were analyzed. That period encompasses all potential onset and cessation dates in any part of the country (Diop 1996). Each time-series is therefore made of 9202 observations (214 d for each year).

\section{DEFINITION OF THE ONSET AND CESSATION DATES}

For the period 1950-1992, the first principal component (PC1) explains $36.3 \%$ of the variance (PC2 6.7\% only), which is a very high percentage given the uneven distribution of daily rainfall. The PC1 timeseries is significantly correlated with all stations (Fig. 1a; 99\% confidence level, after taking into account the reduction of degrees of freedom due to autocorrelation). High loadings are found in a wide belt running from south western Senegal (Casamance) to northern Senegal, the largest corresponding to the west-central part of the country. Only the south-eastern stations and Dakar have correlations below 0.4. This clearly demonstrates that there is a relatively uni- (a) PC1 loading pattern

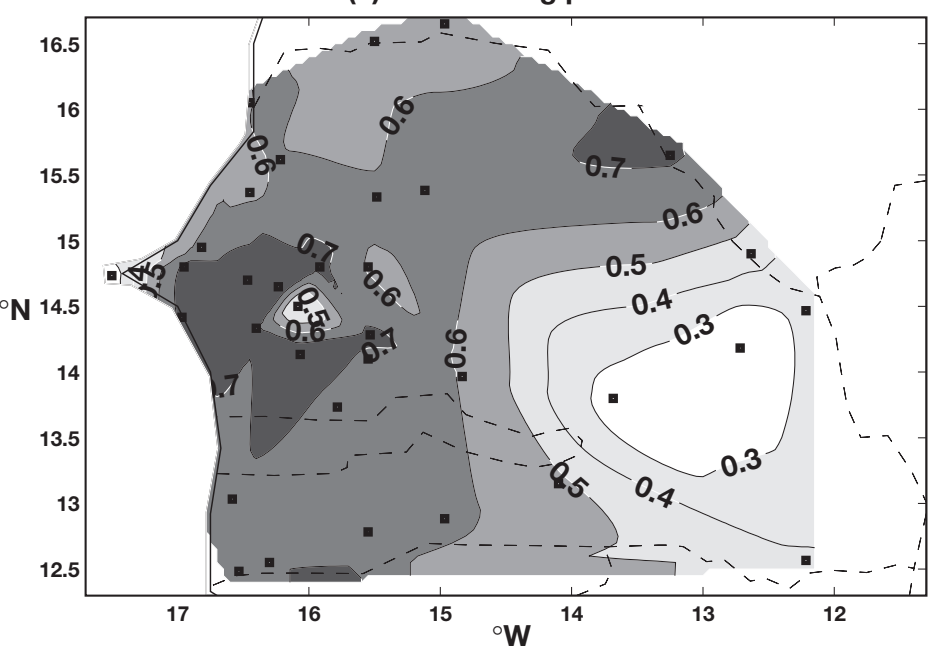

(b) PC1 time-series (extract for years 1950-1957)

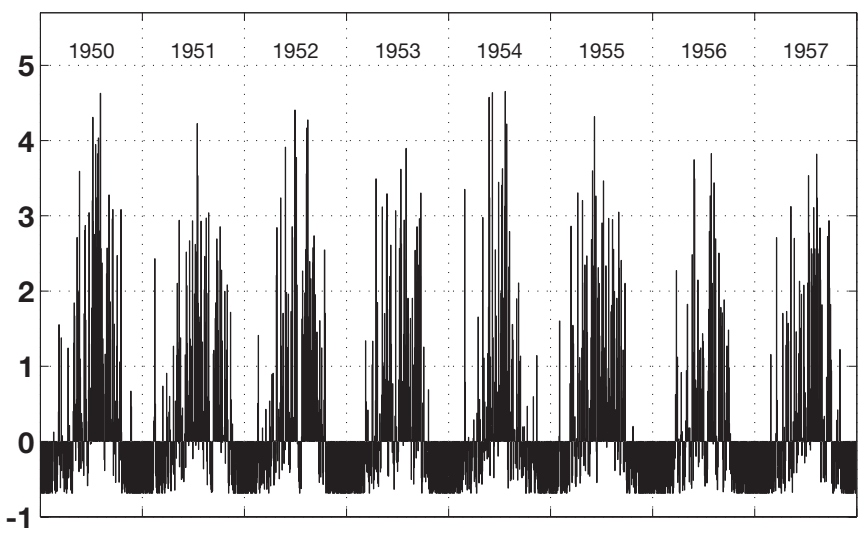

Fig. 1. Principal component analysis of daily square-root transformed rainfall in Senegal (May-November 1950-1992): (a) map of PC1 loading patterns; (b) standardized time-series for the period 1950-1957. In (a), squares show the location of stations, and shaded areas loadings greater than 0.3 

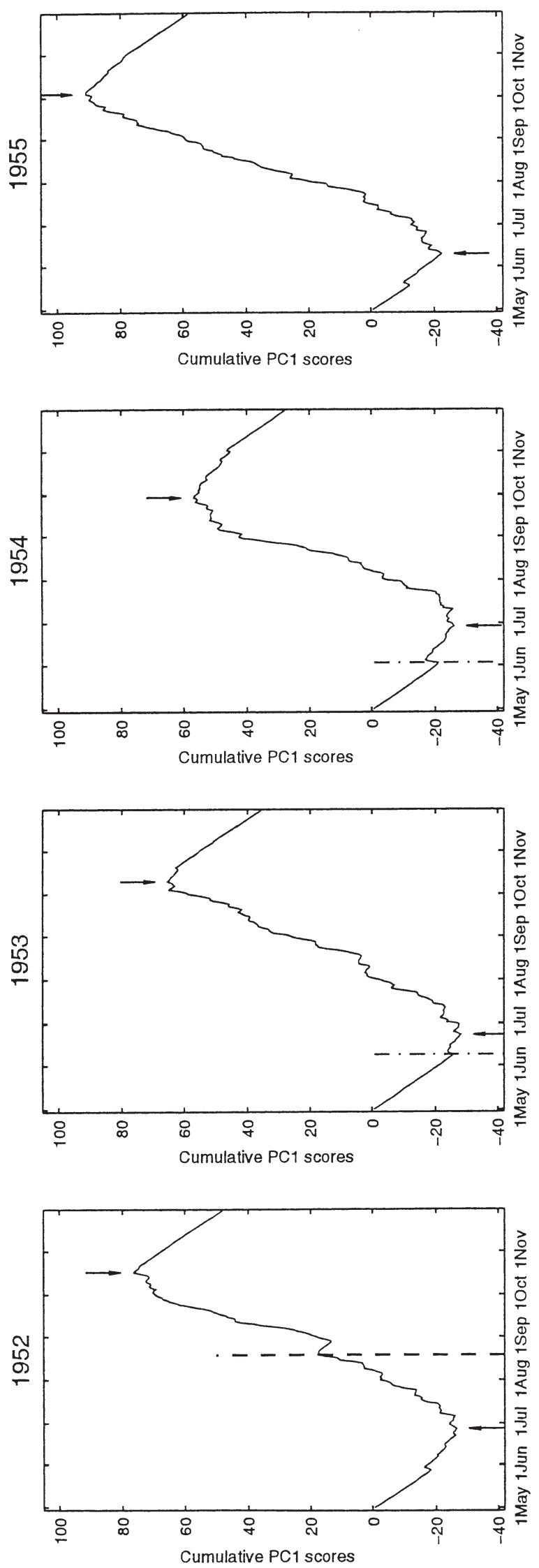

form behavior of the rains all across Senegal. This uniform behavior could partly be seen in terms of timing of the RS, of rain-spell occurrence within the RS, or in terms of interannual variability, the latter being strongly homogenous in the whole Sudan-Sahel (e.g. Nicholson 1986). However, the interannual variability itself accounts for a very small fraction (0.4 to $1.8 \%$ depending on the stations) of the variance of the original daily time-series (after square-root transformation). The north-south elongated pattern of the maximum loadings demonstrates that, despite the gradual reduction in the length of the RS from south to north, the dominant feature of rainfall distribution is that of a relatively simultaneous occurrence of rain spells (or dry spells) in the south and in the north. This makes the identification of onset and cessation dates on a regional, if not national basis, a realistic target.

Based on the above spatial pattern, the standardized PC1 time-series (Fig. 1b) provides a general appraisal of the daily rainfall variability over most of the country, in terms of departures from the long-term daily mean for May-November. We then treated each year individually, and computed the cumulative PC1 values (CPC1) from 1 May. Fig. 2 shows the plots obtained for 4 sample years (1952-1955). Each plot starts with a consistently decreasing trend, denoting persistent negative rainfall anomalies which correspond to the continuation of the dry season. The time-series then pick up; this corresponds to the occurrence of several consecutive days with above-average daily rainfall. This upward trend goes on virtually unabated till a critical point where the time-series start falling again. This signals the end of the RS and the setting up of dryness across most of the country. The 3 consecutive segments thus depict the ending dry season, the RS, and the first leg of the dry season, respectively. Fig. 2 suggests that the onset and cessation of the rains correspond to the minimum point-value and the maximum point-value, respectively, of the daily time-series for each year. In order to test the method, we plotted daily maps of the rainfall recorded from $4 \mathrm{~d}$ before to $4 \mathrm{~d}$ after each year's wet season onset. The average over the $43 \mathrm{yr}$ is presented in Fig. 3. The rainfall increase on Day 1 after onset is almost general, though amounts are much larger in the south than in the north. There is a slight decrease on Day 4, but the contrast between the pre-onset and the post-onset periods is remarkable in all regions apart from the south-east. The same test applied to cessation dates gave a similar contrast between the pre- and post-cessation periods (not shown).

In most years, the onset and cessation are relatively sharp, displaying an unequivocal minimum or maximum. For a few years, however, several consecutive days could qualify as onset or cessation dates, as the 

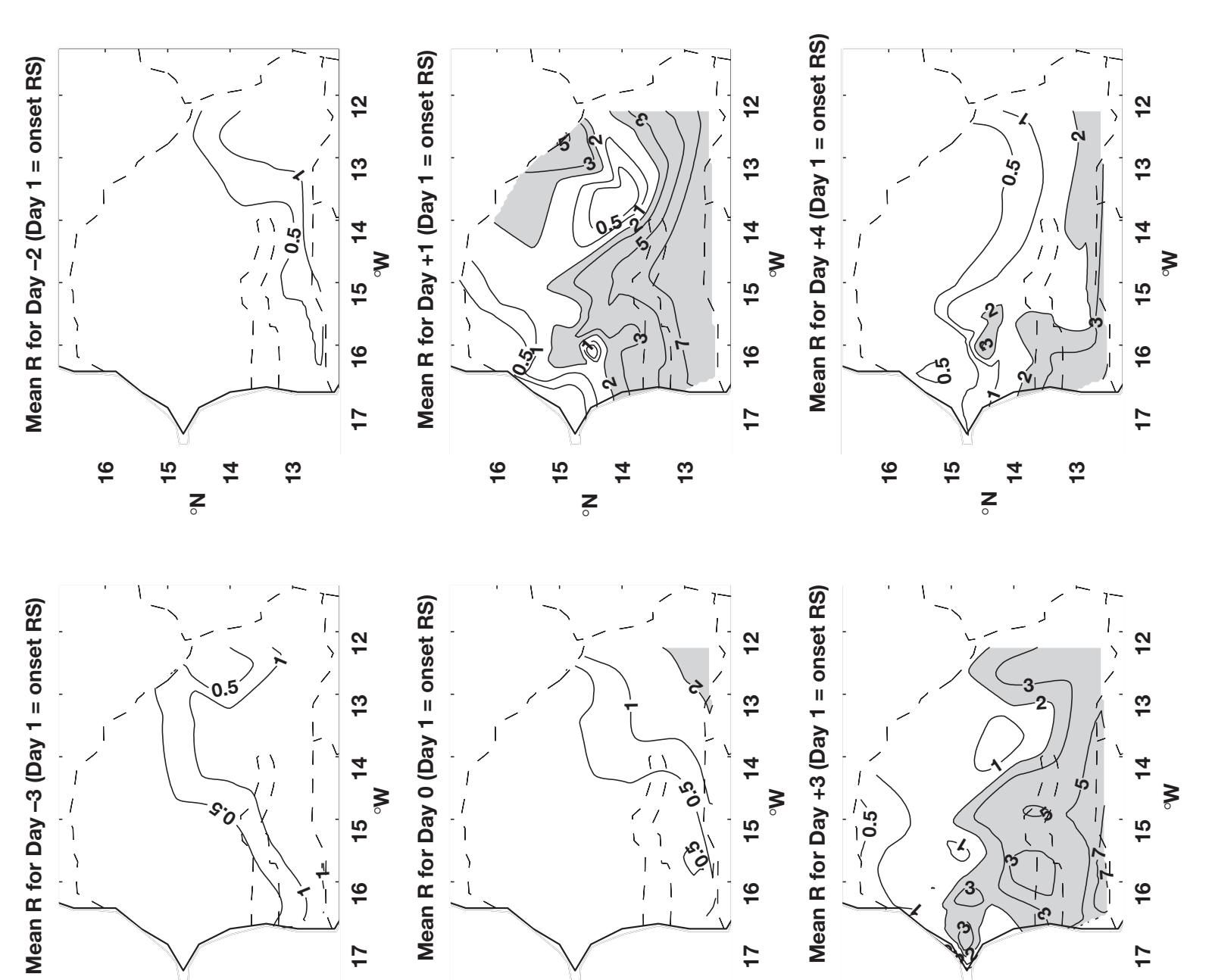

$\stackrel{\infty}{\leftarrow} z^{ \pm} \stackrel{m}{+}$

$\stackrel{\circ}{\stackrel{2}{2}} \stackrel{\square}{\square}$

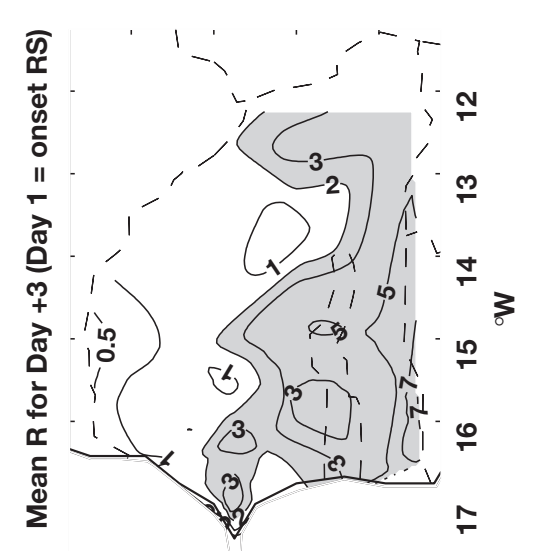

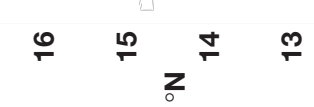
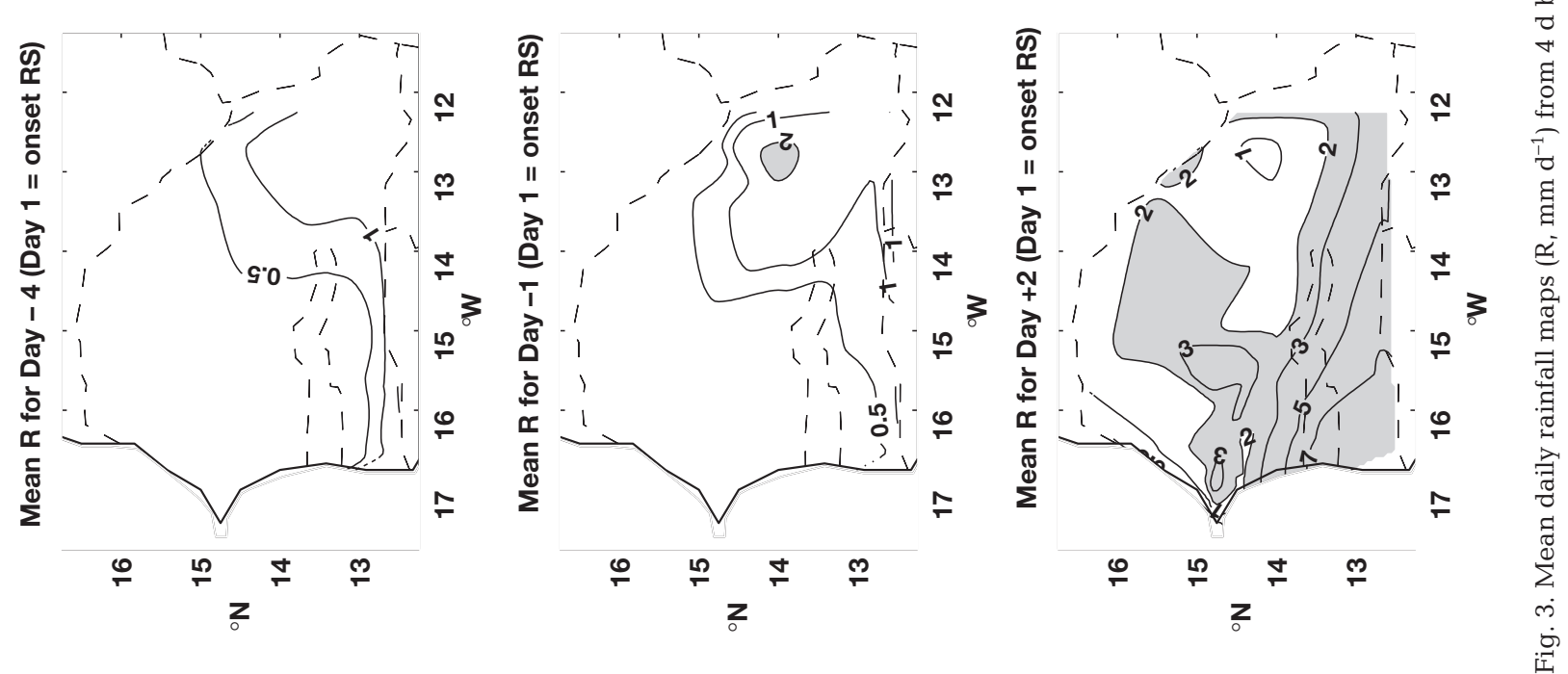


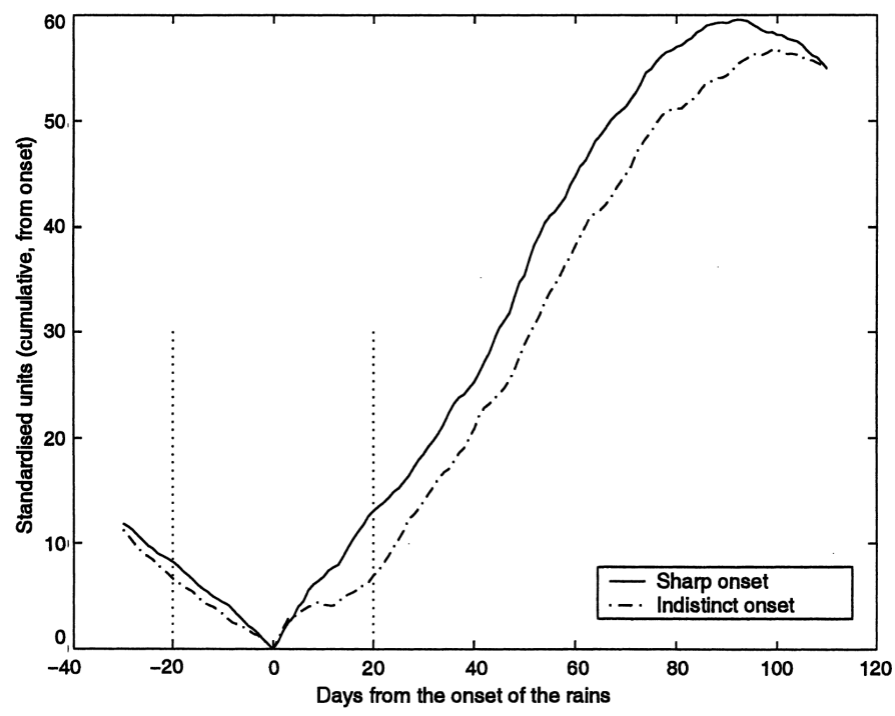

Fig. 4. Composite CPC1 scores for years displaying a sharp onset and indistinct onset. The vertical dotted bars show the period which was considered for the computation of the 'acuteness index' (see text)

time-series does not show definite trends during the onset and cessation phases. To test the robustness of our definition of onset, a $41 \mathrm{~d}$ period centered on the onset date was considered to define an 'acuteness index'. The index is the difference between the value of CPC1 for the onset day and the mean value for the other $40 \mathrm{~d}$ of the period. Large differences denote a sharp onset, while small differences indicate that the onset is more indistinct. Two categories of years were differentiated, based on this index, and the composites plotted (Fig. 4). It is clear that there is not much difference between the 2 types of years on the 4 to $5 \mathrm{~d}$ before and after the onset date. This puts much confidence on the onset date as determined here. The difference becomes greater from 10 to $20 \mathrm{~d}$ after the onset; in other words there are some years (the 'low index' ones) which exhibit a pause in the rains about $2 \mathrm{wk}$ after the onset, though not pronounced and long enough to challenge the definition of onset that we adopted here. Note that this result is quite insensitive to the size of the window (smaller ones were tested, not shown) and to the statistical parameter (median and quintiles were also tested).

In order to assess the spatial representativeness of the interannual variability of the onset and cessation dates, the same method was applied to 3 subsets of the original database. The 34 stations were divided into 3 groups from north to south, with the aim of reflecting the gradient in the average length of the RS. The first sample comprises the 8 northernmost stations (north of $\left.15^{\circ} \mathrm{N}\right)$, the second, 19 stations in central Senegal $\left(13^{\circ} 30^{\prime}-15^{\circ} \mathrm{N}\right)$ and the third, the 7 southernmost sta-
Table 1. Correlations between the interannual variations of the onset/cessation dates in Senegal as a whole, and in the northern, central and southern regions. Period: 1950-1992. Dates are defined based on cumulative PC1 values (CPC1). Significant values at the $99.9 \%$ confidence level are given in bold

\begin{tabular}{|lccc|}
\hline & $\begin{array}{c}\text { North/all- } \\
\text { Senegal }\end{array}$ & $\begin{array}{c}\text { Central/all- } \\
\text { Senegal }\end{array}$ & $\begin{array}{c}\text { South/all- } \\
\text { Senegal }\end{array}$ \\
\hline Onset date & $\mathbf{0 . 6 1}$ & $\mathbf{0 . 9 4}$ & 0.36 \\
Cessation date & $\mathbf{0 . 7 6}$ & $\mathbf{0 . 9 2}$ & $\mathbf{0 . 8 3}$ \\
\hline
\end{tabular}

tions (south of $13^{\circ} 30^{\prime} \mathrm{N}$ ). Raw PC1 time-series for each region correlate very strongly with that obtained for the whole of Senegal. Table 1 displays the correlation between the interannual variability of the onset and cessation dates in each of the 3 regions and that obtained from the 'all-Senegal' data. All correlations are highly significant, with the exception of the onset in the southern region (significant at the 95\% confidence level only). Values close to 1 are found for the central region. This means that the dates based on data for the whole of Senegal somehow reflect those of the various parts of the country, as far as interannual variability is concerned, though they are best representative of central Senegal.

Note that the CPC1 time-series provide other interesting information about the RS (e.g. Figs. 2 \& 6). First, the final CPC1 score (for Day 214 of each year) gives the general performance of the RS, in terms of cumulative rainfall. This is confirmed by the very strong correlation (0.99) between these 43 final CPC1 scores and an all-Senegal May-November seasonal average rainfall index for the same period. Second, the slope between the onset and the cessation dates provides information on the mean rainfall 'intensity' (rainfall per day) during the RS. This aspect may be important, since some plants require quite large water amounts for a relatively short period of time, while others require smaller amounts but over a longer period. Finally, the CPC1 time-series also enable us to identify the major breaks within the RS.

\section{COMPARISON WITH OTHER METHODS}

The time-series of onset and cessation dates based on CPC1 (method D1) were checked against those obtained using 2 other methods. The first one also concentrates on the spatial coherency of rainfall occurrence, but does not take into account the rainfall amounts. This 'percentage method' (D2) is rooted in $20 \mathrm{~d}$ low-pass filtered time-series of the percentage of stations recording significant (at least $1 \mathrm{~mm}$ ) rainfall on 
each day. We propose that onset and cessation dates be the first and last days of the season on which the filtered index is above a given threshold. The determination of the latter remains subjective and was fixed at $30 \%$ of 'wet' stations.

The last method (the 'agroclimatic method', D3) proceeds in a totally different way. On a station-by-station basis, onset and cessation dates are first computed using agroclimatic criteria, following a methodology close to that in use at the International Crops Research Institute for the Semi-Arid Tropics (ICRISAT), Niamey, Niger, and described by Sivakumar (1992). This definition was used by Diop (1996) to assess the spatial patterns of the onset/cessation of the rains in Senegal. The onset is the first of 2 consecutive days totaling at least $20 \mathrm{~mm}$, and not followed by a $7 \mathrm{~d}$ dry spell within the next $30 \mathrm{~d}$. The end of the RS requires at least 7 consecutive dry days, leading to a soil moisture deficit. The local dates are then synthesized on a national basis using either PCA or a simple average, provided the correlation between the individual stations is high enough (as is the case here).

Table 2 provides the mean onset and cessation dates based on the 3 methods. There is a range of only $6 \mathrm{~d}$ between the 3 mean onset dates. For the cessation dates, the range is greater, as shown by a delay of almost $2 \mathrm{wk}$, for the agroclimatic method. The agroclimatic method is more conservative (the rains start later and stop later, similar results being obtained for northern Nigeria by Ati et al. 2002); the interannual variability is also much lower, which is not very realistic. The 2 other methods give very similar results, with respect to both the mean dates and the standard deviation.

On an interannual basis, there is also a fair agreement between the 3 methods. For onset dates, the correlation between D2 and D1 is 0.73 . For D3, figures are slightly lower (0.58 with D1, 0.36 with D2). Similar results are found for the cessation dates, although the correlations tend to be higher (e.g. 0.91 between D1 and D2). All these correlations are statistically significant at the $98 \%$ confidence level.

Table 2. Rainy season mean onset and cessation dates, and their SDs (days), based on all 34 Senegalese stations for the period 1950-1992, and using 3 different methods (see text)

\begin{tabular}{|c|c|c|c|}
\hline & $\begin{array}{l}\text { D3 (agroclimatic } \\
\text { method) }\end{array}$ & $\begin{array}{c}\text { D2 (percentage } \\
\text { method) }\end{array}$ & $\begin{array}{l}\text { D1 (CPC1 } \\
\text { method) }\end{array}$ \\
\hline \multicolumn{4}{|l|}{ Onset } \\
\hline Mean date & $10 \mathrm{Jul}$ & $5 \mathrm{Jul}$ & $4 \mathrm{Jul}$ \\
\hline $\mathrm{SD}(\mathrm{d})$ & 8 & 14 & 16 \\
\hline \multicolumn{4}{|l|}{ End } \\
\hline Mean date & 14 Oct & $1 \mathrm{Oct}$ & 2 Oct \\
\hline $\mathrm{SD}(\mathrm{d})$ & 6 & 11 & 11 \\
\hline
\end{tabular}

The determination of onset and cessation dates based on CPC1 thus compares favorably with other definitions. In addition, we noted very distinct spatial patterns associated with the rains before and after the onset/cessation dates, as deduced from this method. Byun \& Wilhite (1999) advocated the use of rainfall data alone, and of the accumulation of precipitation deficits from climatological means, in the characterization of drought. Therefore, we shall concentrate on the CPC1 method in the rest of the study.

\section{INTERANNUAL VARIABILITY OF ONSET AND CESSATION DATES}

Over the 43 yr period 1950-1992, the cessation dates time-series shows a significant (99\% confidence level) trend (Fig. 5, bottom). It explains as much as $25 \%$ of the total variance. An abrupt shift towards an earlier cessation is found around 1970, the average date for the end of the rains being 9 October for 1950-1969 and 25 September for 1970-1992. There is also a small trend for the onset dates, significant at the $90 \%$ level only. Onset dates tend to occur slightly later at the end of the period, and their interannual variability is also greater (Fig. 5, top). There has thus been a large decrease in the length of the RS in Senegal, as already shown in a station-by-station approach by Diop (1996). However, station data for other Sudano-Sahelian countries do not always display such a decrease. In Mali, Traoré et al. (2000) found a relative stability of the onset and cessation dates between the periods 1959-1978 and 1979-1998. By contrast, Houndenou \& Hernandez (1998) noted a decrease in the wet season duration in northern Benin.

Concomitantly, there is a well-known decrease from the 1960s in seasonal rainfall amounts all across the Sudano-Sahelian belt, Senegal being no exception. However, the relationship between total rainfall amounts and the duration of the RS is not that straightforward. Fig. 6 shows 3 contrasted cases. In 1988 and 1989, the total rainfall amounts were quite similar (i.e. close to the long-term 1950-1992 average, as shown by final $y$-coordinates close to zero for the 2 timeseries). However, in 1988 the onset occurred more than 1.5 mo later than in 1989. A late onset is thus not necessarily associated with a low seasonal rainfall amount. In 1988, there were heavy falls in August and early September (as shown by the steep slope between the onset and cessation dates in Fig. 6, which indicates greater rainfall amounts per rain day, or more rain days). These falls contributed to 'save' the season. In 1990, the RS was significantly longer than in 1988 (onset on 12 July, as compared to 27 July; cessation on 6 October, as compared to 21 September). Yet the 

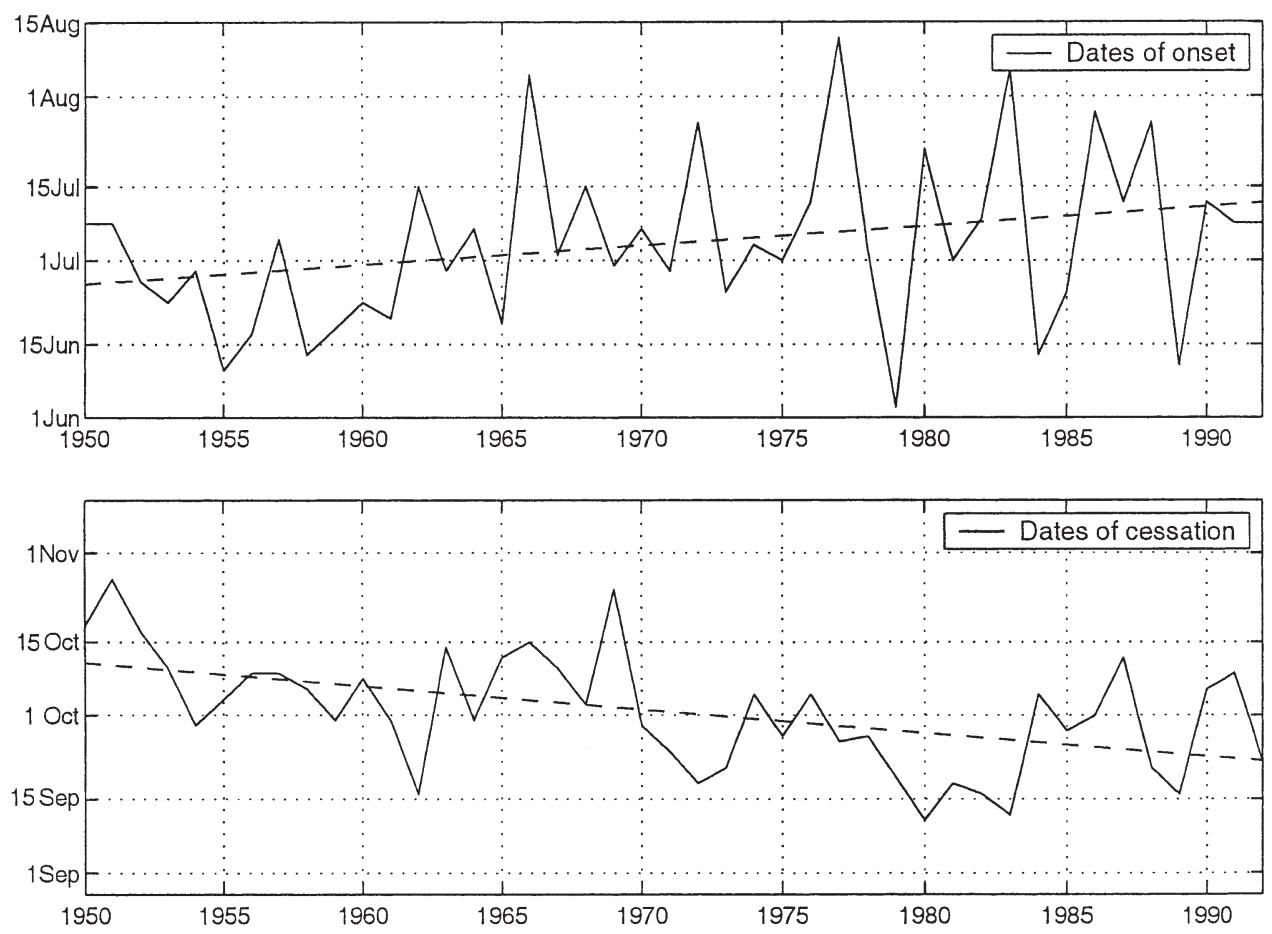

Fig. 5. Time-series of all-Senegal onset and cessation dates (1950-1992) based on CPC1 scores

overall performance of the rains was poor, due to small and discontinued rainfalls. Note that, among the 3 years, 1988 recorded the lowest yields for both the major food crop (millet: $521 \mathrm{~kg} \mathrm{ha}^{-1}$, as compared to 664 in 1989 and 629 in 1990) and the major cash crop (groundnut: $794 \mathrm{~kg} \mathrm{ha}^{-1}$, as compared to 1072 in 1989

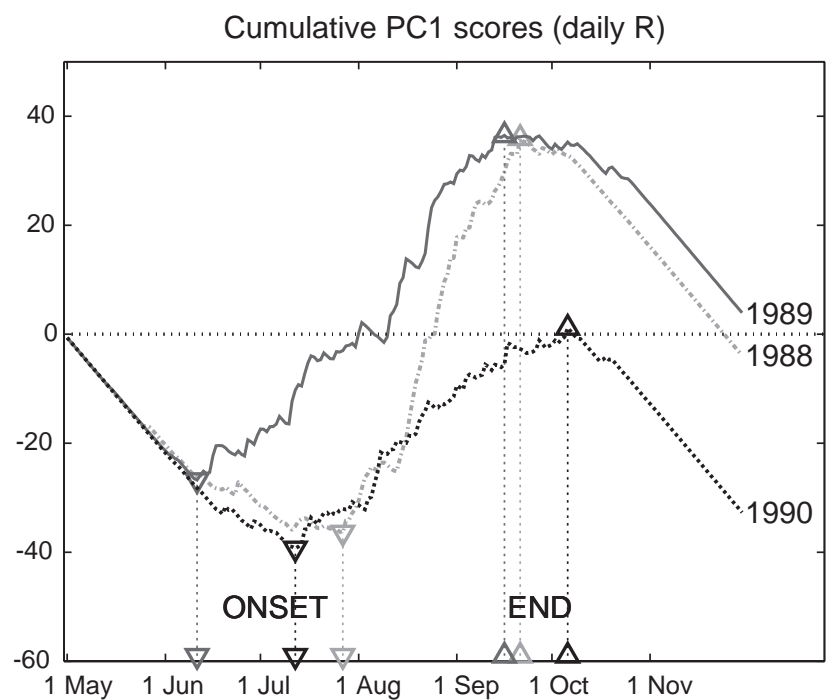

Fig. 6. Comparison of CPC1 scores for 1988, 1989 and 1990, with indication of onset and cessation dates (triangles) and 966 in 1990 [FAO data; http://apps.fao.org]). This example demonstrates that the timing of the rains may have as much importance as the total rainfall amount for agricultural production.

From Table 3, it is evident that the correlation between onset, cessation, duration and total rainfall amounts is not as high as expected. For the period 1950-1992, common trends artificially increase correlation coefficients (especially between cessation dates and total rainfall), but when we are restricted to the 'dry' decades 1970-1992, the correlations are much lower for both the cessation dates and the duration. For

Table 3. Correlation coefficients between the interannual variations of various descriptors of the rainy season in Senegal. Total amount is based on the final value of CPC1 for each year. Significant values at the 95\% (99\%) confidence level are given in bold (shaded)

\begin{tabular}{|lcrc|}
\hline & Cessation & Duration & Total amount \\
\hline $\mathbf{1 9 5 0 - 1 9 9 2}$ & & & \\
Onset & -0.16 & $-\mathbf{0 . 8 5}$ & $\mathbf{- 0 . 4 0}$ \\
Cessation & & $\mathbf{0 . 6 6}$ & $\mathbf{0 . 6 3}$ \\
Duration & & & $\mathbf{0 . 6 5}$ \\
$\mathbf{1 9 7 0 - 1 9 9 2}$ & & & \\
Onset & -0.08 & $\mathbf{- 0 . 9 0}$ & $\mathbf{- 0 . 5 1}$ \\
Cessation & & $\mathbf{0 . 5 1}$ & 0.17 \\
Duration & & & $\mathbf{0 . 5 2}$ \\
& & & \\
\hline
\end{tabular}




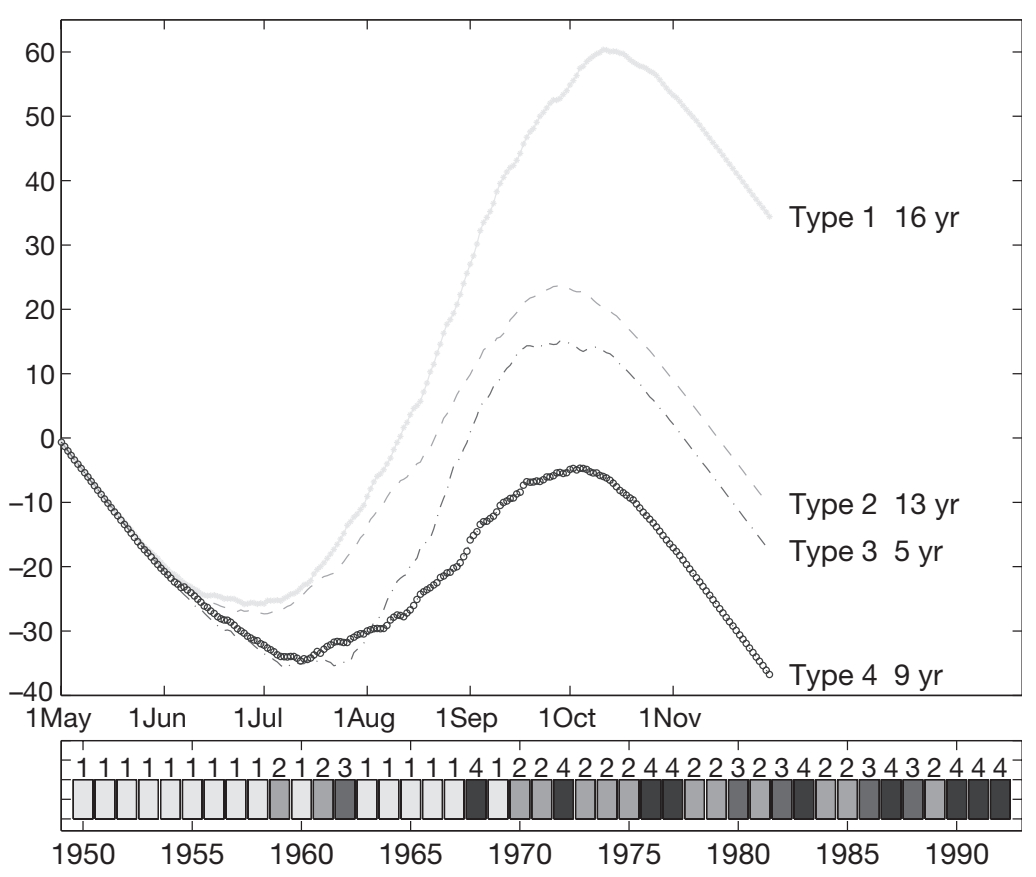

Fig. 7. Typing of years based on the characteristics of the rainy season. Top panel: composite scores for 4 types of years, according to cluster analysis. Bottom panel: categorization of each year of the period 1950-1992

Type 1), and the RS terminates early. Type 4 corresponds to 'bad' seasons which combine unfavorable conditions (late onset, quite early cessation, and low mean rainfall per day). Type 3 also presents a late onset and rather early cessation, but rainfall during the season is quite heavy, which results into an average overall rainfall amount, quite close to that observed in Type- 2 years. The distribution of the 4 types of years is not random, with all Type 1 ('good') years concentrated before 1970, and all Type-4 ('bad') years between 1968 and 1992. Note the contrasted categorizing of the 3 years presented in Fig. 6 (1988, 1989, 1990).

Before the true onset of the rains, there are on some occasions wet spells which make local farmers think that the RS is settling. They are conveniently referred to as 'false starts' and are easily identified on the CPC1 time-series. For routine identification, we considered all the days prior to the onset for which the CPC1 value was lower than that of all the 7 previous and the 7 next days. Such days signal the start of a wet period (i.e. with rainfall averaged over

the onset dates, only $25 \%$ of the variance is in common with the total rainfall amount. For the cessation dates, the percentage is as low as $3 \%$. This limited dependence of total rainfall amounts on the length of the wet season indicates that the 'rain efficiency', which both reflects the mean intensity per rain day and the frequency of rainfall events during the RS, is a key component of the general performance of the RS. An important result is also that, when long-term trends are discarded, the interannual variability of the total rainfall amount, and that of the duration of the RS, are much more affected by the variations of the onset dates than by those of the cessation dates. This feature has also been noted in neighboring Mali (Traoré et al. 2000). It is in line with the larger standard deviation displayed by the onset dates, as compared to the cessation dates (Table 2).

In order to summarize the characteristics of the RS, and to classify the years according to these characteristics, we performed a cluster analysis of the $43 \mathrm{yr}$, based on the cumulative scores, and using 'Ward' criterion to regroup years into clusters (Fig. 7). For clarity, only the 4 major types are shown here. Type 1 corresponds to 'good' years with both an early onset and a late cessation, as well as an overall good performance of the rains. Type 2 displays a similarly early onset, but within season rainfall activity is quite low (compare the slope between July and September with that of the next $7 \mathrm{~d}$ above the long-term mean). For the 1950-1992 period, 19 cases of false starts were identified, in 16 yr (slightly more than once every 3 yr). The time-series do not exhibit any particular trend: 11 of the $19 \mathrm{yr}$ are found in the first half of the period. Note that on some occasions several false starts may occur, as in 1962.

Pronounced dry spells (which can be designated as 'breaks' since they are identified here almost on a country basis) can also be easily located using CPC1 plots; they appear as several days of downward CPC1 trend within the RS. Breaks start after a relative maximum is found in the time-series, with respect to the previous and next $11 \mathrm{~d}$. Based on this definition, 29 cases of breaks were found between 1950 and 1992 (Fig. 8). They are concentrated in the early part of the RS (June-July), although some can be found occasionally in the middle (e.g. in 1952, there was a total absence of rains between 19 and 29 August, as displayed in Fig. 2). As for false starts, there is no longterm trend in the frequency of breaks.

\section{CONCLUSION}

This study has demonstrated that principal component analysis applied on daily square-root transformed data provides useful, large-scale information about the 


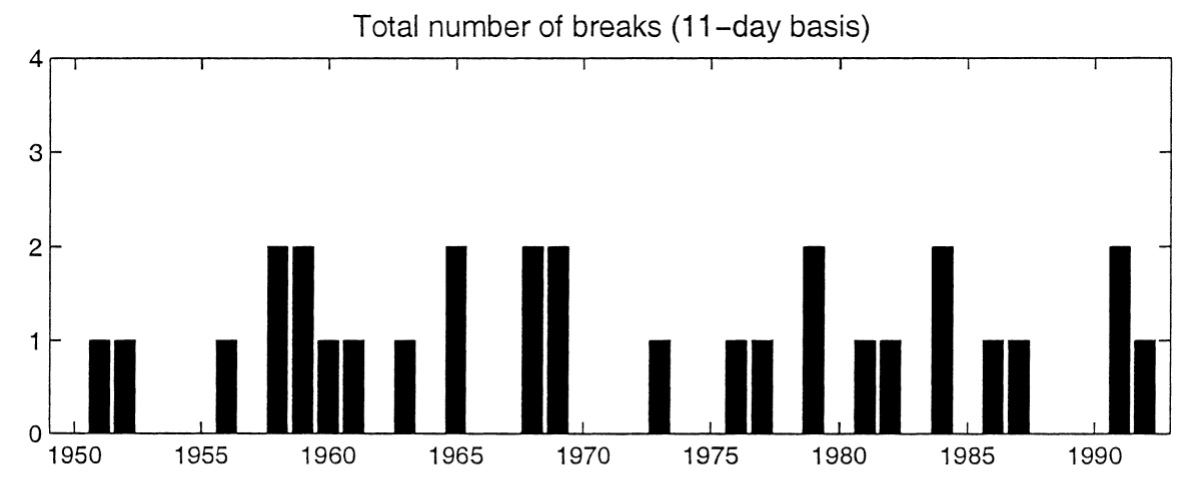

Frequency of breaks by 20 day periods

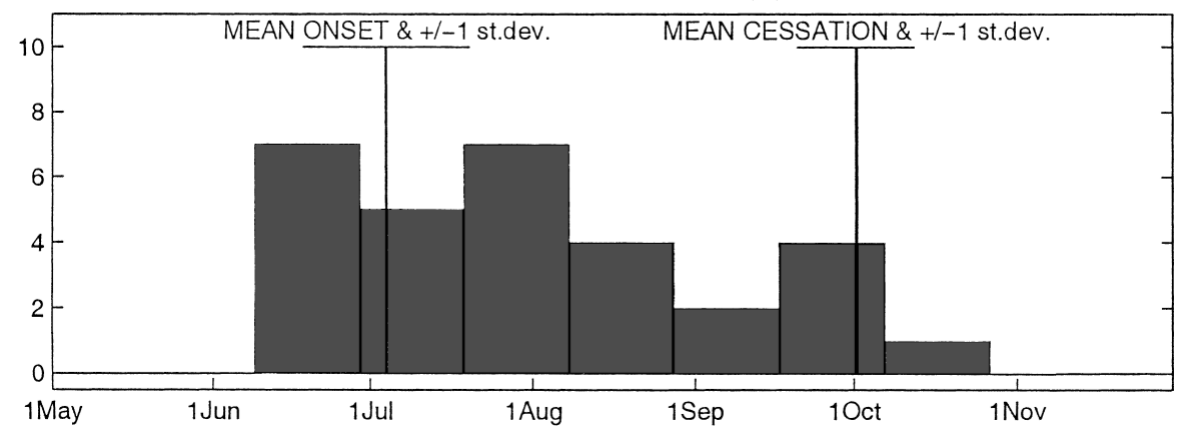

Fig. 8. Frequency of dry spells ('breaks') within the rainy season. Top panel: 1950-1992 time-series; bottom panel: $20 \mathrm{~d}$ frequency distribution with respect to mean onset and cessation dates

general behavior of the rainy season. Of particular interest is the determination of onset and cessation dates on a regional basis, for further analysis of the associated atmospheric dynamics. The regional indexes of onset and cessation are based on points of change in the timeseries of the PC1 for each year, where the lowermost (uppermost) point denotes the onset (cessation) of the rains. This simple, non-local definition compares favorably with other criteria, such as those based on a regional mean of the dates determined from local agroclimatic assessments. False starts and dry periods within the rainy season can also be monitored.

The fair spatial representativeness of the onset and cessation indexes indicates that, in Senegal, despite large discrepancies in the duration of the rainy season from south to north, there exist definite pulses of the rainbelt. This suggests that the movement of the InterTropical Convergence Zone over Senegal, as in other parts of the Sudano-Sahelian region (Sultan \& Janicot 2000) includes sudden northward/southward shifts, rather than consisting only of slow migration.

Over 1950-1992, the mean onset, mostly representative of central Senegal, occurs on 4 July, and the cessation on 2 October. There exists quite a large interannual variability, which is stronger for the onset (standard deviation of $16 \mathrm{~d}$ ) than for the end of the rains. This variability is partly in the form of a shift at the beginning of the 1970 s towards an earlier cessation, a somewhat later onset and a reduced duration of the rains. Though this coincides with a strong decrease in seasonal rainfall amounts, the correlation between amounts and onset/cessation dates on a year-to-year basis is not as high as expected. Total duration of the rains depends more on the onset than on the cessation. Evidence is provided that yields may be as much affected by variations in the timing of the rains as by changes in the total rainfall amount. Other features in the distribution of the rains, such as 'false starts' and intermediate dry spells, may also have some impact; however, they do not exhibit any significant change in their frequency over 1950-1992.

The dates of onset and cessation fixed using the present method are of course not relevant to every station of the country (and the method is not meant for that); but they correspond to the most apparent and enduring shifts of the rainbelt. As aggregate indexes, they are therefore likely to be the reflection of quite abrupt circulation changes, which may not be unpredictable. Marengo et al. (2001) demonstrated, for the Amazonian region of Brazil, that onset and cessation of the rains are associated with trade-wind intensity over the Atlantic ocean, and large-scale sea-surface temperature anomalies. Such features are currently being investigated for Senegal. 


\section{LITERATURE CITED}

Ati OF, Stigter CJ, Oladipo EO (2002) A comparison of methods to determine the onset of the growing season in Northern Nigeria. Int J Climatol 22:731-742

Bärring L (1988) Regionalization of daily rainfall in Kenya by means of common factor analysis. Int J Climatol 8:371-389

Byun HR, Wilhite DA (1999) Objective quantification of drought severity and duration. J Clim 12:2747-2756

Diop M (1996) A propos de la durée de la saison des pluies au Sénégal. Sécheresse 7:7-15

Dodd DES, Jolliffe IT (2001) Early detection of the start of the wet season in semiarid tropical climates of western Africa. Int J Climatol 21:1251-1262

Hendon HH, Liebmann B (1990) A composite study of onset of the Australian summer monsoon. J Atmos Sci 47: $2227-2240$

Holland GJ (1986) Interannual variability of the Australian summer monsoon at Darwin: 1952-82. Mon Weather Rev 114:594-601

Houndenou C, Hernandez K (1998) Modification de la saison pluvieuse dans l'Atakora (1961-1990). Un exemple de sécheresse au nord-ouest du Bénin. Sécheresse 9:23-34

Joseph PV, Eischeid JK, Pyle RJ (1994) Interannual variability of the onset of the Indian Summer monsoon and its association with atmospheric features, El Niño, and sea surface temperatures. J Clim 7:81-105

Marengo JE, Liebmann B, Kousky VE, Filizola NP, Wainer IC (2001) Onset and end of the rainy season in the Brazilian Amazon Basin. J Clim 14:833-849

Mhita MS, Nassib IR (1987) The onset and end of rains in Tanzania. In: Proceedings of the First Technical Conference

Editorial responsibility: Clare Goodess,

Norwich, United Kingdom on Meteorological Research in Eastern and Southern Africa. Kenya Meteorology Department, Nairobi, p 33-37 Nicholls N (1984) A system for predicting the onset of the north Australian wet-season. Int J Climatol 4:425-435

Nicholls N, McBride JL, Ormerod RJ (1982) On predicting the onset of the Australian wet monsoon at Darwin. Mon Weather Rev 110:14-17

Nicholson SE (1986) The spatial coherence of African rainfall anomalies: Interhemispheric teleconnections. J Climate Appl Meteor 25:1365-1381

Omotosho JB (1992) Long-range prediction of the onset and end of the rainy season in the West African Sahel. Int J Climatol 12:369-382

Omotosho JB, Balogun AA, Ogunjobi K (2000) Predicting monthly and seasonal rainfall, onset and cessation of the rainy season in West Africa using only surface data. Int J Climatol 20:865-880

Samba A (1998) Les logiciels DHC de Diagnostic Hydrique des Cultures. Prévision des rendements du mil en zones soudano-sahéliennes de l'Afrique de l'Ouest. Sécheresse 9:281-288

Sivakumar MVK (1992) Climate change and implications for agriculture in Niger. Clim Change 20:297-312

Stern RD, Dennett MD, Garbutt DJ (1981) The start of the rains in West Africa. J Climatol 1:59-68

Sultan B, Janicot S (2000) Abrupt shift of the ITCZ over West Africa and intra-seasonal variability. Geophys Res Lett 27: 3353-3356

Traoré SB, Reyniers FN, Vaksmann M, Kouressy M, Yattara K, Yorote A, Sidibe A, Kone B (2000) Adaptation à la sécheresse des écotypes locaux de sorgho du Mali. Sécheresse 11:227-237

Submitted: March 7, 2002; Accepted: November 15, 2002

Proofs received from author(s): January 10, 2003 